NOTICE: This is the accepted manuscript of the following article: Montenegro J, Phips R. Highlights from the 52nd EUCHEM conference on stereochemistry, Bürgenstock, Switzerland, May 2017. Chem Commun. 2017 [doi:10.1039/c7cc90258a]. This article may be used for non-commercial purposes in accordance with RSC Terms and Conditions for self-archiving

\title{
Highlights from the 52nd EUCHEM conference on stereochemistry, Bürgenstock, Switzerland, May 2017
}

\author{
Javier Montenegro ${ }^{1 *}$, Robert J. Phipps ${ }^{2 *}$
}

1 Centro Singular de Investigación en Química Biolóxica e Materiais Moleculares (CIQUS) and Departamento de Química Orgánica, Universidade de Santiago de Compostela, 15782 Santiago de Compostela (Spain). E-mail: javier.montenegro@usc.es

2 Department of Chemistry, University of Cambridge, Lensfield Road, Cambridge, CB2 1EW, UK. E-mail: rjp71@ @ cam.ac.uk

The strong wind that was blowing in Brunnen the last $4^{\text {th }}$ of May was precluding the storm of ideas and creativity that would later fall over the participants of the $52^{\text {th }}$ edition of the Bürgenstock conference. The Bürgenstock conference is a truly unique event. A meeting held in a beautiful and relaxing landscape where the Alps merge with the crystalline sweet water of the Luzern Lake, researchers from the best Universities, Institutes and companies came to Brunnen for the $52^{\text {nd }}$ Bürgenstock conference from all over the globe. At six o'clock sharp in the evening of the Sunday, all the participants were ready to start with a welcome dinner in the "Fronalp-Saal" of the wonderful Waldstätterhof hotel. The conference started by a short introductory speech of the president, Professor Bert W. E. Meijer, who revealed that it was Prof Deiderich who invited him to give a talk at the 1996 Bürgenstock meeting, and speculated whether it may be one of this year's speakers who would invite him as guest of honour in twenty years' time! In his speech, Prof. Meijer already highlighted the importance and the reputation of the occasion by explaining the format of this singular event. Built on plenary lectures, a key feature is the half an hour set aside after each lecture for discussions in which more than twenty questions could be asked of a single speaker. Another feature is short talks by young JSP (Junior Scientists Participation) fellows and two poster sessions to trigger interactions and potentially initiate collaborations. This was going to be a singular conference and we all noticed it from the very beginning.

After dinner, Prof. Chirik (Princeton) started the conference with his lecture titled "Catalysis with Earth Abundant Metals: New Opportunities for Synthesis and Mechanism". Prof Chirik's lecture focussed on using control of electronic structure using ligand design to modulate the reactivity in complexes with earth abundant metals. A 
particular focus was placed on redox-active iron complexes, where electronic communication between the ligand and metal centre enabled 'metal-ligand cooperativity' and remarkable new chemical reactivity. ${ }^{1}$ He first described the group's development of Fe-catalysed [2+2] cycloadditions of unactivated alkenes using such complexes ${ }^{2}$ and then demonstrated elegant studies on how cobalt complexes incorporating these ligands allow 1,1-diboration of terminal alkynes. ${ }^{3}$ In the second half of the lecture, he demonstrated exciting work showing that $\mathrm{C}-\mathrm{H}$ borylation reactions, of the type that most commonly employ expensive iridium, can in fact be carried out with base metals if the right ligand can be developed. This was shown on both $\mathrm{sp}^{2} \mathrm{C}-\mathrm{H}$ borylation using cobalt pincer complexes, ${ }^{4}$ and benzylic borylation, which was achieved by switching to diimine ligands. ${ }^{5}$ Not only are these metals much cheaper, but were also shown to provide access to complementary products as well regioselectivities in some cases. Finally, a switch to nickel diimine complexes allowed access to a remarkable triborylation of benzylic $\mathrm{C}-\mathrm{H}$ bonds! ${ }^{6}$ Chirik's lecture was followed by a welcome cocktail where the participants could meet old and new friends and share their first impressions of the conference.

Monday morning the session was opened by Prof. Kay Severin (EPFL, Lausanne) with his lecture titled "Synthetic Chemistry with Laughing Gas". Prof Severin began by introducing the properties of nitrous oxide, which is a strong oxidant but with a high activation energy that can often limit the chemistry available to it. Yet its ready availability coupled with the fact that it is an ozone depletor and very efficient greenhouse gas make it an attractive feedstock for synthetic chemists. ${ }^{7}$ After describing use of nitrous oxide as an oxidant for the cross coupling of Grignard reagents, ${ }^{8}$ he revealed that $N$-heterocyclic carbenes are able to activate nitrous oxide, which enables subsequent cleavage of the $\mathrm{N}-\mathrm{O}$ bond by a vanadium complex. Remarkably, the resulting complex upon heating undergoes rearrangement with cleavage of the $\mathrm{N}-\mathrm{N}$ bond meaning that the $\mathrm{NHC}$ and vanadium are together able to split all three bonds in the $\mathrm{N}_{2} \mathrm{O}$ molecule. ${ }^{9}$ This activation of $\mathrm{N}_{2} \mathrm{O}$ with NHCs was then shown to have very nice application in the synthesis of azoimidazolium dyes. ${ }^{10}$ In the final section of the lecture, Prof Severin first demonstrated how $\mathrm{N}_{2} \mathrm{O}$ can be harnessed for the synthesis of triazines and that alkynyltriazines are remarkably good functional analogues of ynamides, showing exciting applications in diversity oriented synthesis and asymmetric catalysis. ${ }^{11}$

After a short break the next speaker, Prof. Joost Reek from Amsterdam University, started his talk with a simple but motivating question: "Can we use supramolecular chemistry to solve the upcoming challenges in transition metal catalysis?" This challenge was firstly approached by the application of supramolecular chemistry to control transition metal catalysts via the second coordination sphere; i.e by putting the catalyst in confined spaces $^{12}$ and by substrate organization. ${ }^{13}$ Challenging hydroformylation reactions were addressed in both concepts to demonstrate the power of supramolecular 
catalysis. For example, by only tuning the size of the cages around a catalyst, the Reek group could switch the regioselectivity in the hydroformylation of un-functionalized substrates providing proof of concept of modulated supramolecular regioselective catalysis (Fig. 2). The lecture continued on the development of supramolecular approaches to achieve extreme high local concentrations of the catalyst, a strategy that allowed the achievement of $1.1 \mathrm{M}$ concentration of the gold metal catalyst. ${ }^{14}$ This approach was applied for the controlled synthesis of nanoparticles in supramolecular capsules $^{15}$ and in the development of self-assembled nanospheres that function as nanoconcentrators by pre-organizing substrates and catalysts. ${ }^{16}$ The lecture elaborated on this concept as the inspiration for the development of artificial enzymes and the presentation was concluded with recent results of the Reek's group in the aqueous proton reduction at low overpotential. ${ }^{17}$ The afterwards discussion provided a good conceptual sketch on the "artificial enzymes" that the Reek group is currently targeting.

With a touch of Australian humour and some confusions with a certain fictional secret agent, Prof. David Craik (not Daniel, not Craig) started his fabulous lecture about the "magical" cyclic peptides found in the Kalata-Kalata African plant. ${ }^{18,19}$ During several fascinating, and sometimes risky journeys, in places like Katmandú or Vietnam for the collection of samples of plants and the corresponding characterization; Prof. Craik and co-workers realized that several of these plants were more resistant to the attack of insects. The question now was why? Was there any cause behind these observations? And more importantly, can we learn and perhaps benefit from this particular behaviour? The answers to these questions were hidden in a compact and robust class of miniproteins called the "cyclotides". ${ }^{18,20}$ These cyclic templates, characterized by their internal cystine knot, revealed to the Craik group their hidden secrets such as antimocrobial, cytoxic and antiviral properties. In a great effort of generous creativity, the Craik group managed to graft different bioactive peptides sequences into the cyclic framework of these robust cyclotides (Fig. 3). ${ }^{21}$ These grafted cyclotides stabilized the corresponding bioactive peptide sequences and were able to trigger the intended bio-interaction with either extra or intracellular targets. Following on from this concept and by the appropriate genetic manipulation, it was possible to develop plants expressing the pharmacologically active cyclotides that can be boiled to produce a tea that could be enriched with the customized bioactive peptide drugs. The final dream of Prof. Craik: to grow antiviral or anticancer drugs in your backyard petunias garden. Impressive! Don’t you think?

The two-hour poster session on Monday afternoon featured twenty-two diverse posters. Five of these were selected for short ( 7 minute) oral presentations beforehand. Anyone running over time faced the mooing of a Swiss cow over the audio system, which in most cases was sufficient to wrap up proceedings. These were all JSP (Junior Scientist Participant) Fellows and were Philipp Heretsch (Freie Universität Berlin), Rafal Klajn 
(Weizmann Institute of Science), Jiri Misek (Charles University, Prague), Robert Phipps (University of Cambridge) and Pablo Rivera-Fuentes (ETH Zurich).

Professor Tanja Weil, Director at the Max Planck Institute for Polymer Research in Mainz, delivered the last lecture of the day. The presentation was devoted to the rational design of new materials that allow the external control and manipulation of living cells. Cationic amphiphilic peptides were found to enhance the retroviral gene transfection by forming fibrilar self-assembled structures on top of the target cells. ${ }^{22}$ These assemblies presumably minimized the negative/negative repulsive interactions between the infecting virus and the host cell. Interesting amphiphilic dendrimer patches were also developed to enhance the uptake of bio-functional molecules in the host cells. ${ }^{23}$ The future directions for the next generation materials in the Weil group were presented with new grafted copolymers that introduce the "all in one molecule" concept. These "macro" molecules are capable of displaying different "epitopes" along the same scaffold and thus they could display multiple functions. A polypeptide scaffold bearing pegylated chains for biocompatibility, phosphonium moieties for mitochondrial targeting and ruthenium metal centres was developed as a photosensitizer for photodynamic therapy. ${ }^{24}$ Prof. Weil finally introduced her research efforts towards the search of the perfect nano-diamond hybrid. The objective in the Weil lab is to develop new synthetic approaches and applications of these elusive materials, that one-day will perform as a fully inert quantum multi-probe in living systems. ${ }^{25}$

The first morning lecture of Tuesday was given by Prof. Thorsten Bach (Technische Universität München) titled "Chirality and light: Enantioselective Catalysis of Photochemical Reactions". Prof. Bach commenced with a thorough but very accessible introduction to the fundamentals of photochemistry which set his lecture up very nicely, as well as outlining the challenges for asymmetric catalysis using photochemistry. ${ }^{26} \mathrm{He}$ described his groups ingenious approach of designing chiral triplet sensitising molecules based on the Kemp's triacid scaffold such that interaction with the substrate would enable both photosensitisation as well as facial selectivity in the subsequent radical reaction. ${ }^{27}$ The generality of this approach was demonstrated with recent examples of powerful intermolecular [2+2] cycloadditions using modified catalysts ${ }^{28,29}$ and it was shown that on a sunny day this chemistry can even be triggered by sunlight on the roof of their building! He then detailed the successes of their alternative strategy of utilising a chiral Lewis acid to enable enone [2+2] cycloadditions. This was developed after observing a significant shift in UV absorption upon complexation and selectively exciting only the complexed enone, which is in a chiral environment. ${ }^{30,31}$ Finally, the Brønsted acid catalysed [2+2] cycloaddition of enone dithianes was shown to offer intriguing possibilities for combining asymmetric Brønsted acid catalysis with photochemistry. ${ }^{32}$ After lunch, Tuesday afternoon was free for exploring the beautiful area around Brunnen 
and the weather was perfect for this.

The second lecture of the session was an outstanding presentation by Prof. Jörn Piel (Munchen Technical University). Prof. Jörn Piel dedicated his lecture to one of the best drug producers in the world: the bacteria. ${ }^{33}$ Are there any new drug leads in the underexplored regions of the immense bacterial diversity? Can we understand the mechanism of their intriguing enzymatic machineries? Can we perhaps exploit enzymes and pathways from these "talented producers" for synthetic purposes? Theonella swinhoei is a marine sponge containing dozens of different natural products and living in association with numerous bacteria. ${ }^{34}$ The polytheonamides isolated from this animal are a group of hydrophobic peptide toxins that include numerous unusual amino acids (Fig. 4). The Piel group showed that these natural peptides are generated by 49 posttranslational modifications, including multiple amino acid epimerization reactions and even methylations of inactive carbon centres. ${ }^{34}$ Intriguingly all these different modifications on the ribosomal peptide were tackled by only seven enzymes. ${ }^{35}$ Polytheonamides are members of a larger peptide family, for which Piel showed further examples of unusual modifications. Finally, in order to identify the true producer, Piel and collaborators applied a single cell workflow methodology. ${ }^{36}$ This strategy allowed the identification of an as-yet unculturable Entotheonella bacterium as the symbiotic guest behind the synthesis of many of the important bioactive natural products detected for their sponge host.

After dinner, the Tuesday evening lecture was given by Tim Jamison (MIT) entitled "Synthesis Design through the Lens of Flow Chemistry - When, Why and How". Prof. Jamison commenced with a very well explained introduction to flow chemistry, comparing batch and flow and emphasising the merits of each. To illustrate his points on the advantages of flow, he used an astonishing example from this group of "A ThreeMinute Synthesis and Purification of Ibuprofen". This was enabled by continuous-flow processing and encompassed five stages: three bond forming steps, a workup and a separation, with the steps each yielding $>90 \% .{ }^{37} \mathrm{He}$ then moved on to detail a case study of the DIBAL-H reduction of esters to aldehydes, a transformation that is highly desirable but often capricious in conventional batch, but which Prof. Jamison showed can be carried out reliably time-after-time in flow after careful optimisation. ${ }^{38} \mathrm{He}$ went on to show impressive applications of flow chemistry in photoredox catalysis ${ }^{39}$ and synthesis using gases, 40 both being areas where switching to flow offers many practical advantages. Finally, he described their pioneering collaboration with chemical engineers at MIT develop end-to-end continuous pharmaceutical manufacturing, enabled by flow chemistry. This started off with a set-up the size of a shipping container ${ }^{41}$ but which they have since reduced in a very short time-scale to a unit the size of a fridge/freezer which is able to produce thousands of doses per day. ${ }^{42}$ 
Professor Jennifer Prescher started the Wednesday session with a colourful lecture that shed light on how to expand the synthetic toolkit for multicomponent molecular imaging. ${ }^{43}$ She suggested that to tackle these problems, a key challenge would be to develop chemical reporters that are orthogonal to each other. The Prescher group has recently focused on the cyclopropene functionality for bio-orthoghonal ligation with tetrazines via an inverse-electron-demand Diels-Alder cycloaddition. ${ }^{44}$ Interestingly, this reaction is compatible with azide/alkyne click reactions and the cyclopropene moiety constitutes a small, stable and broadly compatible motif for biomolecule imaging. The lecture then switched to luciferin bioluminescent probes that were screened for selective processing by mutant firefly luciferases. ${ }^{45}$ The strategy involved the synthesis of different luciferin analogues with steric, electronic or aromatic modifications. After confirmation of the intrinsically luminescent behaviour of the probes, these artificial luciferins were subjected to screening with mutated residues. Subsequent optimization afforded three enzyme/substrate pairs with improved selective recognition capabilities. Remarkably, these novel orthogonal pairs enabled cell type differentiation in imaging experiments. ${ }^{45}$ The current efforts of the Prescher team are now focused on improving the robustness and brightness of these chemical tools. Prof. Prescher finally pointed out that the great in vivo signal to noise ratio of these bioluminescent probes make them attractive candidates for multicomponent imaging in living organisms.

Prof. Luc Brunsveld from the Technical University of Eindhoven delivered the last lecture of the Wednesday morning session. Prof. Brunsveld lecture was aimed towards the understanding of supramolecular protein/protein interactions and their application in functional systems. Prof. Brunsveld pointed out the importance of the spatial organization for the complex behaviour of proteins in terms of protein scaffolding as well as for signal transduction. Building on this concept, the Brunsveld group decided to study the supramolecular "druggable" motifs of the CFTR (cystic fibrosis transmembrane conductance regulator), a membrane protein that, if abnormally retained in the endoplasmic reticulum, might cause cystic fibrosis. ${ }^{46,47}$ The in vitro detailed characterization of the binding motifs between the known 14-3-3 protein with the CFTR, allowed the external induced enhancement of this supramolecular interaction by using a natural product (fusicoccin-A). This stabilized 14-3-3/CFTR protein complex stimulates the traffic of the mutant CFRT and therefore inhibits its undesired accumulation in the endoplasmic reticulum. ${ }^{46}$ Different supramolecular binding complexes between curcubituril and FGG-tagged proteins were also investigated and used for protein hetero or homo-dimerization and thus modulate the activation of the functional enzymes ensembles (Fig. 5) ${ }^{47-51}$ The lecture finished with a collection of selected examples of supramolecular protein assembly triggered by DNA-origami, supramolecular wires of proteins and different discotic self-assembled tubular constructs with functional 
properties. $^{52}$

The first Thursday morning lecture was from Prof. Karl-Heinz Altmann (ETH Zurich) entitled "Total Synthesis and Functional Exploration of Macrocyclic Natural Products". The lecture's central message of the medical importance of macrocyclic natural products was conveyed using three illustrative examples from Prof. Altmann's research group. The first concerned mycolactones A and B and described the total synthesis ${ }^{53}$ and subsequent extensive biological studies on the natural products and related analgoues. ${ }^{54}$ These studies provided a greatly increased understanding of the pathogenesis of the highly destructive skin disease Buruli ulcer. The second story concerned zampanolide, which possesses a similar mode of anti-cancer action to Taxol. Synthetic studies efficiently demonstrated which parts of the molecule were crucial for activity ${ }^{55}$ and led to a brilliant crystal structure of a Tubulin-Zampanolide complex. Finally, the synthesis of rhizoxin was enabled by ring-closing alkyne metathesis ${ }^{56}$ and a crystal structure of its complex with Tubulin solved, elegantly providing a structural basis for rational design of important anti-cancer agents. ${ }^{57}$

The second Thursday morning lecture was delivered by Prof. Motomu Kanai (University of Tokyo) entitled "Aerobic Oxygen-Driven Functionalization of Small Molecules and Proteins". Catalysis was the key focus of Prof. Kanai's talk, emphasising it as an enabling link between the molecular sciences and the life sciences. He began by introducing earlier work from his group which developed a three component catalytic system to enable the aerobic oxidation of amines to give imines. ${ }^{58}$ This system was found to be very effective for cleaving serine residues in peptides, which occured at room temperature at near-neutral $\mathrm{pH}$ values. Site-selectivity for serine residues was excellent, and the methodology was effective even on the protein ubiquitin, strongly suggesting that this has the potential to be a very powerful method for site-selective scission of large biomolecules. ${ }^{59} \mathrm{He}$ also detailed their serendipitous discovery that tryptophan residues in some cases react with one of the reagents in their system and how this finding was developed into a powerful tryptophan-selective bioconjugation method which was again shown to be viable on proteins. ${ }^{60}$ In the final part of the lecture, Prof Kanai detailed their exciting studies on developing dye-inspired switchable photooxygenation catalysts that selectively bind to aggregated proteins, such as amyloid $\beta$-protein $(A \beta)$, which is implicated in Alzheimer's disease. Remarkably, when their catalysts bind to $A \beta$, internal bond rotation of the catalyst is restricted and this extends the life of the excited state of the photocatalyst, enabling production of singlet oxygen. The outcome is that the progression of aggregation is inhibited and advanced biological studies provided strong evidence of the therapeutic potential of this unique approach. ${ }^{61}$

The next speaker was Prof. Frank Würthner from the Center for Nanosystems Chemistry 
at Würzbürg University. The Würthner group develops new methodologies to integrate dyes in nanostructured materials for multiple applications such as sensors, transistors and solar cells. ${ }^{62}$ However, in this occasion, Prof. Würthner focused his lecture on the design principles of the supramolecular architectures that are required to overcome the three major limitations in the final functional systems: the length and size control, the controlled integration of different molecules and the prediction of properties. ${ }^{62}$ Perylene dyes, the molecular muse of the Würthner lab, rapidly appeared, this time as part of an interesting cyclophane host that provided a well-defined cavity for the corresponding molecular guest. The different electronics of these encapsulated molecules allowed the "on-off" switching of the fluorescence of the corresponding supramolecular complexes. ${ }^{63}$ Larger perylene bisimide macrocycles containing different number of chromophores were prepared, carefully separated and studied in the presence of different solvents. ${ }^{64}$ In aromatic solvents, the macrocycles with and even number of perylenes were folded in a rope-like twisted conformation. Intriguingly, when there was an odd number of perylenes, the folding did not take place with the exception of the largest most flexible nonamer. ${ }^{64}$ Prof. Würthner also presented several nice examples of $\pi$-stacks in organogels and merocyanine oligomers. The perylene motif was finally commented in the fabrication of supramolecular block co-polymers, in which planar and twisted perylenes were combined in well-defined patterns to afford ultra-long self-assembled nanowires. ${ }^{65}$

The second two-hour poster session, on Thursday afternoon, featured 21 posters. Five of these were selected for short oral presentations and these were given by Pol Besenius (Johannes Gutenberg- Universität Mainz), Thomas Hermans (University of Strasbourg), Frank Kotch (Pfizer), Corinna Schindler (University of Michigan), Corey Stephenson (University of Michigan).

The closing lecture was from Prof. Jan van Hest (Eindhoven University) with an impressive talk on artificial cells that was the icing on the cake for the 2017 Bürgenstock conference. Professor van Hest defined the cell as a very complex factory where many different chemical transformations are happening at the same time. ${ }^{66}$ The separation from the external media and the compartmentalization of these chemical processes were a key step in the evolution of self-sustained living systems. Therefore, Prof. van Hest started his lecture by explaining the implementation of amphiphilic block co-polymers as more robust, versatile and stable materials for the preparation of membranes and polymersomes. ${ }^{66}$ The lessons learnt in the van Hest group on this exciting topic identified one key challenge: the "controlled permeability" of these polymersomes. It was crucial in the fabrication of artificial organelles, containing enzymes or functional proteins, to find ways to communicate with the exterior for the uptake of chemical reagents and the delivery of the corresponding products. The elegant strategy of the van Hest group consisted of the encapsulation of semipermeable polymerosomes within a bigger polymer 
vesicle, affording in a simple but beautiful design a simple eukaryotic cell mimic. In this minimal cell, the "organelle" multicompartmentalization allowed the functional coupling of incompatible enzymes that could participate in cascade enzymatic reactions. ${ }^{67}$ Prof. van Hest then switched to the preparation of stomatocytes-like polymersomes with entrapped metal nanoparticles. These novel particles were formed after the dialysis that was needed for the removal of the organic solvents during polymersome preparation. ${ }^{68}$ Metal catalysis inside the cavity of these particular polymersomes resulted in the expulsion of the gas products (i.e. $\mathrm{O}_{2}$ ) from the stomatocyte valve. The final ensemble performed as amazing self-propelled nanoparticles with externally regulated speed by means of temperature ${ }^{69}$ or by rationally designed enzymatic reaction networks. ${ }^{68}$

After this great firework display of functional nano-containers and self-sustained motile nanoparticles, it was time to wrap up the official proceedings and hand over the reins to the vice-president. Long-standing committee members Prof Helma Wennemers and Prof Jerome Lacour announced that they would be standing down: their fantastic contributions to this and previous meetings were well recognised by all. Additionally, the vicepresident for next year's meeting was announced as being Prof Veronique Gouverneur. After this, the participants moved to the closing cocktail reception. It was already five days of plenary lectures, extensive discussions, short talks, fruitful poster sessions and hiking trips in the beautiful surroundings. It is not easy to summarize the knowledge and feeling that you attain from attending the Bürgenstock Conference. However, in Brunnen somebody already mentioned something like: "That was so wonderful".

R.J.P. and J.M. are very grateful to the organising committee of the 2017 Burgenstock conference for the award of JSP fellowships. R.J.P is grateful to the Royal Society for a University Research Fellowship. J.M. is grateful to MINECO for a Ramón y Cajal fellowship. 
1 P. J. Chirik, Angew. Chem. Int. Ed., 2017, 56, 5170-5181.

2 J. M. Hoyt, V. A. Schmidt, A. M. Tondreau and P. J. Chirik, Science, 2015, 349, 960-963.

3 S. Krautwald, M. J. Bezdek and P. J. Chirik, J. Am. Chem. Soc., 2017, 139, 38683875.

4 J. V. Obligacion, S. P. Semproni, I. Pappas and P. J. Chirik, J. Am. Chem. Soc., 2016, 138, 10645-10653.

5 W. N. Palmer, J. V. Obligacion, I. Pappas and P. J. Chirik, J. Am. Chem. Soc., 2016, 138, 766-769.

6 W. N. Palmer, C. Zarate and P. J. Chirik, J. Am. Chem. Soc., 2017, 139, 2589-2592.

$7 \quad$ K. Severin, Chem. Soc. Rev., 2015, 44, 6375-6386.

8 G. Kiefer, L. Jeanbourquin and K. Severin, Angew. Chem. Int. Ed., 2013, 52, 63026305.

9 A. G. Tskhovrebov, E. Solari, M. D. Wodrich, R. Scopelliti and K. Severin, J. Am. Chem. Soc., 2012, 134, 1471-1473.

10 A. G. Tskhovrebov, L. C. E. Naested, E. Solari, R. Scopelliti and K. Severin, Angew. Chem. Int. Ed., 2015, 54, 1289-1292.

11 F. G. Perrin, G. Kiefer, L. Jeanbourquin, S. Racine, D. Perrotta, J. Waser, R. Scopelliti and K. Severin, Angew. Chem. Int. Ed., 2015, 54, 13393-13396.

12 S. H. A. M. Leenders, R. Gramage-Doria, B. de Bruin and J. N. H. Reek, Chem. Soc. Rev., 2015, 44, 433-448.

13 P. Dydio, R. J. Detz and J. N. H. Reek, J. Am. Chem. Soc., 2013, 135, 10817-10828.

14 R. Gramage-Doria, J. Hessels, S. H. A. M. Leenders, O. Tröppner, M. Dürr, I. Ivanović-Burmazović and J. N. H. Reek, Angew. Chem. Int. Ed., 2014, 53, 1338013384.

15 V. Bocokic, A. Kalkan, M. Lutz, A. L. Spek, D. T. Gryko and J. N. H. Reek, Nat. Commun., 2013, 4:2670.

16 Q.-Q. Wang, S. Gonell, S. H. A. M. Leenders, M. Dürr, I. I. Burmazović and J. N. H. Reek, Nat. Chem., 2016, 8, 225-230.

17 R. Becker, S. Amirjalayer, P. Li, S. Woutersen and J. N. H. Reek, Sci. Adv., 2016, 2:e1501014.

18 D. J. Craik and J. Du, Curr. Opin. Chem. Biol., 2017, 38, 8-16.

19 A. S. Ravipati, A. G. Poth, S. Troeira Henriques, M. Bhandari, Y.-H. Huang, J. Nino, M. L. Colgrave and D. J. Craik, J. Nat. Prod., 2017, 80, 1522-1530.

20 G. Bhardwaj, V. K. Mulligan, C. D. Bahl, J. M. Gilmore, P. J. Harvey, O. Cheneval, G. W. Buchko, S. V. S. R. K. Pulavarti, Q. Kaas, A. Eletsky, P.-S. Huang, W. A. Johnsen, P. J. Greisen, G. J. Rocklin, Y. Song, T. W. Linsky, A. Watkins, S. A. Rettie, X. Xu, L. P. Carter, R. Bonneau, J. M. Olson, E. Coutsias, C. E. Correnti, T. Szyperski, D. J. Craik and D. Baker, Nature, 2016, 538, 329-335.

21 A. G. Poth, L. Y. Chan and D. J. Craik, Biopolymers, 2013, 100, 480-491.

22 M. Yolamanova, C. Meier, A. K. Shaytan, V. Vas, C. W. Bertoncini, F. Arnold, O. Zirafi, S. M. Usmani, J. A. Müller, D. Sauter, C. Goffinet, D. Palesch, P. Walther, N. R. Roan, H. Geiger, O. Lunov, T. Simmet, J. Bohne, H. Schrezenmeier, K. Schwarz, L. Ständker, W.-G. Forssmann, X. Salvatella, P. G. Khalatur, A. R. Khokhlov, T. P. J. Knowles, T. Weil, F. Kirchhoff and J. Münch, Nat. Nanotech., 
2013, 8, 130-136.

23 B. A. G. Hammer, Y. Wu, S. Fischer, W. Liu, T. Weil and K. Müllen, ChemBioChem, 2017, 18, 960-964.

24 S. Chakrabortty, B. K. Agrawalla, A. Stumper, N. M. Vegi, S. Fischer, C. Reichardt, M. Kögler, B. Dietzek, M. Feuring-Buske, C. Buske, S. Rau and T. Weil, J. Am. Chem. Soc., 2017, 139, 2512-2519.

25 Y. Wu, F. Jelezko, M. B. Plenio and T. Weil, Angew. Chem. Int. Ed., 2016, 55, 6586-6598.

26 R. Brimioulle, D. Lenhart, M. M. Maturi and T. Bach, Angew. Chem. Int. Ed., 2015, 54, 3872-3890.

27 A. Bauer, F. Westkämper, S. Grimme and T. Bach, Nature, 2005, 436, 1139-1140.

28 M. M. Maturi and T. Bach, Angew. Chem. Int. Ed., 2014, 53, 7661-7664.

29 A. Tröster, R. Alonso, A. Bauer and T. Bach, J. Am. Chem. Soc., 2016, 138, 78087811.

30 R. Brimioulle and T. Bach, Science, 2013, 342, 840-843.

31 R. Brimioulle, A. Bauer and T. Bach, J. Am. Chem. Soc., 2015, 137, 5170-5176.

32 C. Brenninger, A. Pöthig and T. Bach, Angew. Chem. Int. Ed., 2017, 56, 4337-4341.

33 M. C. Wilson and J. Piel, Chem. Biol., 2013, 20, 636-647.

34 M. F. Freeman, C. Gurgui, M. J. Helf, B. I. Morinaka, A. R. Uria, N. J. Oldham, H.G. Sahl, S. Matsunaga and J. Piel, Science, 2012, 338, 387-390.

35 M. F. Freeman, M. J. Helf, A. Bhushan, B. I. Morinaka and J. Piel, Nat. Chem., 2017, 9, 387-395.

36 M. C. Wilson, T. Mori, C. Rückert, A. R. Uria, M. J. Helf, K. Takada, C. Gernert, U. A. E. Steffens, N. Heycke, S. Schmitt, C. Rinke, E. J. N. Helfrich, A. O. Brachmann, C. Gurgui, T. Wakimoto, M. Kracht, M. Crüsemann, U. Hentschel, I. Abe, S. Matsunaga, J. Kalinowski, H. Takeyama and J. Piel, Nature, 2014, 506, 58-62.

37 D. R. Snead and T. F. Jamison, Angew. Chem. Int. Ed., 2015, 54, 983-987.

38 D. Webb and T. F. Jamison, Org. Lett., 2012, 14, 568-571.

39 H. Seo, M. H. Katcher and T. F. Jamison, Nat. Chem., 2016, 9, 453-456.

40 T. A. McTeague and T. F. Jamison, Angew. Chem. Int. Ed., 2016, 55, 15072-15075.

41 S. Mascia, P. L. Heider, H. Zhang, R. Lakerveld, B. Benyahia, P. I. Barton, R. D. Braatz, C. L. Cooney, J. M. B. Evans, T. F. Jamison, K. F. Jensen, A. S. Myerson and B. L. Trout, Angew. Chem. Int. Ed., 2013, 52, 12359-12363.

42 A. Adamo, R. L. Beingessner, M. Behnam, J. Chen, T. F. Jamison, K. F. Jensen, J.C. M. Monbaliu, A. S. Myerson, E. M. Revalor, D. R. Snead, T. Stelzer, N. Weeranoppanant, S. Y. Wong and P. Zhang, Science, 2016, 352, 61-67.

43 D. M. Patterson and J. A. Prescher, Curr. Opin. Chem. Biol., 2015, 28, 141-149.

44 D. M. Patterson, L. A. Nazarova, B. Xie, D. N. Kamber and J. A. Prescher, J. Am. Chem. Soc., 2012, 134, 18638-18643.

45 K. A. Jones, W. B. Porterfield, C. M. Rathbun, D. C. McCutcheon, M. A. Paley and J. A. Prescher, J. Am. Chem. Soc., 2017, 139, 2351-2358.

46 L. M. Stevers, C. V. Lam, S. F. R. Leysen, F. A. Meijer, D. S. van Scheppingen, R. M. J. M. de Vries, G. W. Carlile, L. G. Milroy, D. Y. Thomas, L. Brunsveld and C. Ottmann, Proc. Natl. Acad. Sci. U. S. A., 2016, 113, E1152-E1161.

47 R. P. G. Bosmans, J. M. Briels, L.-G. Milroy, T. F. A. De Greef, M. Merkx and L. Brunsveld, Angew. Chem. Int. Ed., 2016, 128, 9045-9049. 
48 D. T. Dang, H. D. Nguyen, M. Merkx and L. Brunsveld, Angew. Chem. Int. Ed., 2013, 52, 2915-2919.

49 M. Ramaekers, S. P. W. Wijnands, J. L. J. van Dongen, L. Brunsveld and P. Y. W. Dankers, Chem. Commun., 2015, 51, 3147-3150.

50 A. den Hamer, L. J. M. Lemmens, M. A. D. Nijenhuis, C. Ottmann, M. Merkx, T. F. A. De Greef and L. Brunsveld, ChemBioChem, , 2017, 18, 331-335.

51 P. de Vink, J. Briels, T. Schrader, L. Milroy, L. Brunsveld and C. Ottmann, Angew. Chem. Int. Ed., 2017, DOI: 10.1002-anie.201701807.

52 K. Petkau-Milroy, D. A. Uhlenheuer, A. J. H. Spiering, J. A. J. M. Vekemans and L. Brunsveld, Chem. Sci., 2013, 4, 2886-2891.

53 P. Gersbach, A. Jantsch, F. Feyen, N. Scherr, J.-P. Dangy, G. Pluschke and K.-H. Altmann, Chem. Eur. J., 2011, 17, 13017-13031.

54 R. Bieri, N. Scherr, M.-T. Ruf, J.-P. Dangy, P. Gersbach, M. Gehringer, K.-H. Altmann and G. Pluschke, Acs Chem. Biol., 2017, 12, 1297-1307.

55 D. Zurwerra, F. Glaus, L. Betschart, J. Schuster, J. Gertsch, W. Ganci and K.-H. Altmann, Chem. Eur. J., 2012, 18, 16868-16883.

56 C. M. Neuhaus, M. Liniger, M. Stieger and K.-H. Altmann, Angew. Chem. Int. Ed., 2013, 52, 5866-5870.

57 A. E. Prota, K. Bargsten, J. F. Diaz, M. Marsh, C. Cuevas, M. Liniger, C. Neuhaus, J. M. Andreu, K. H. Altmann and M. O. Steinmetz, Proc. Natl. Acad. Sci. U. S. A., 2014, 111, 13817-13821.

58 T. Sonobe, K. Oisaki and M. Kanai, Chem. Sci., 2012, 3, 3249-3255.

59 Y. Seki, K. Tanabe, D. Sasaki, Y. Sohma, K. Oisaki and M. Kanai, Angew. Chem. Int. Ed., 2014, 53, 6501-6505.

60 Y. Seki, T. Ishiyama, D. Sasaki, J. Abe, Y. Sohma, K. Oisaki and M. Kanai, J. Am. Chem. Soc., 2016, 138, 10798-10801.

61 A. Taniguchi, Y. Shimizu, K. Oisaki, Y. Sohma and M. Kanai, Nat. Chem., 2016, 8, 974-982.

62 F. Würthner, C. R. Saha-Möller, B. Fimmel, S. Ogi, P. Leowanawat and D. Schmidt, Chem. Rev., 2016, 116, 962-1052.

63 P. Spenst and F. Würthner, Angew. Chem. Int. Ed., 2015, 54, 10165-10168.

64 P. Spenst, R. M. Young, B. T. Phelan, M. Keller, J. Dostál, T. Brixner, M. R. Wasielewski and F. Würthner, J. Am. Chem. Soc., 2017, 139, 2014-2021.

65 D. Görl, X. Zhang, V. Stepanenko and F. Würthner, Nat. Commun., 2017, 6:7009.

66 B. C. Buddingh and J. C. M. van Hest, Acc. Chem. Res., 2017, 50, 769-777.

67 R. J. R. W. Peters, M. Marguet, S. Marais, M. W. Fraaije, J. C. M. van Hest and S. Lecommandoux, Angew. Chem. Int. Ed., 2013, 53, 146-150.

68 M. Nijemeisland, L. K. E. A. Abdelmohsen, W. T. S. Huck, D. A. Wilson and J. C. M. van Hest, ACS Cent. Sci., 2016, 2, 843-849.

69 Y. Tu, F. Peng, X. Sui, Y. Men, P. B. White, J. C. M. van Hest and D. A. Wilson, Nat. Chem., 2017, 9, 480-486. 


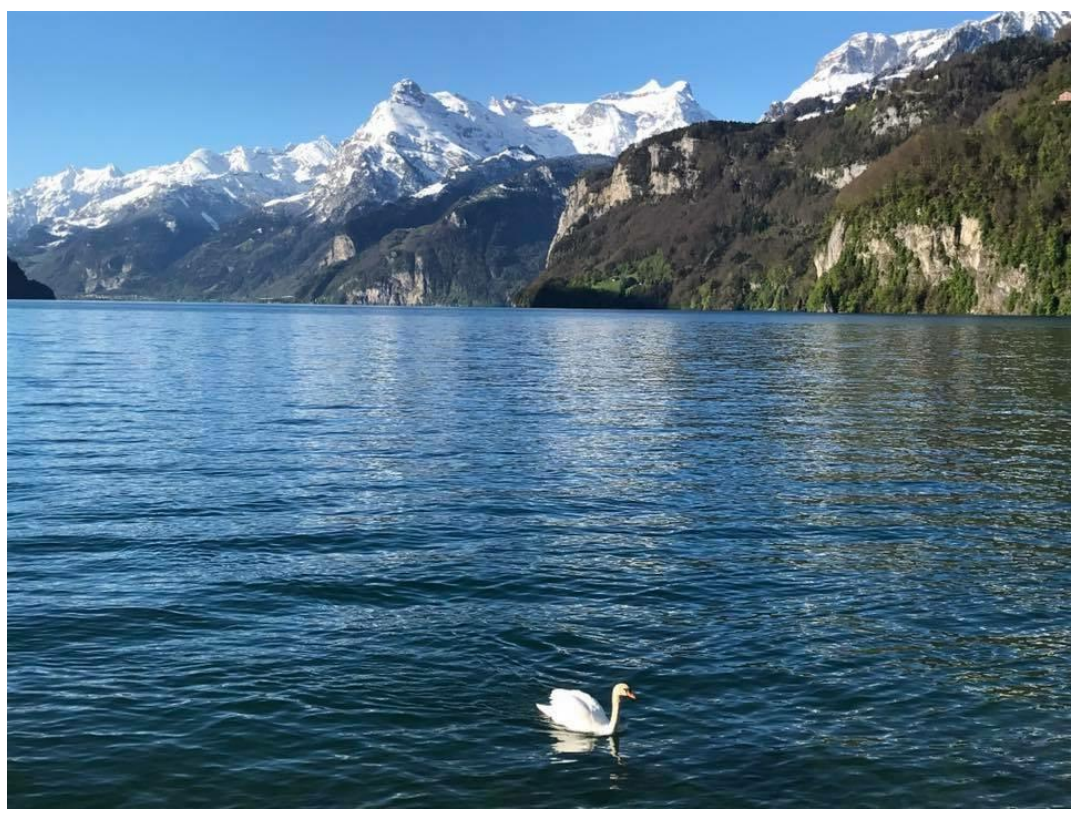

Figure 1. View of the Luzern Lake in front of the Conference Hall.

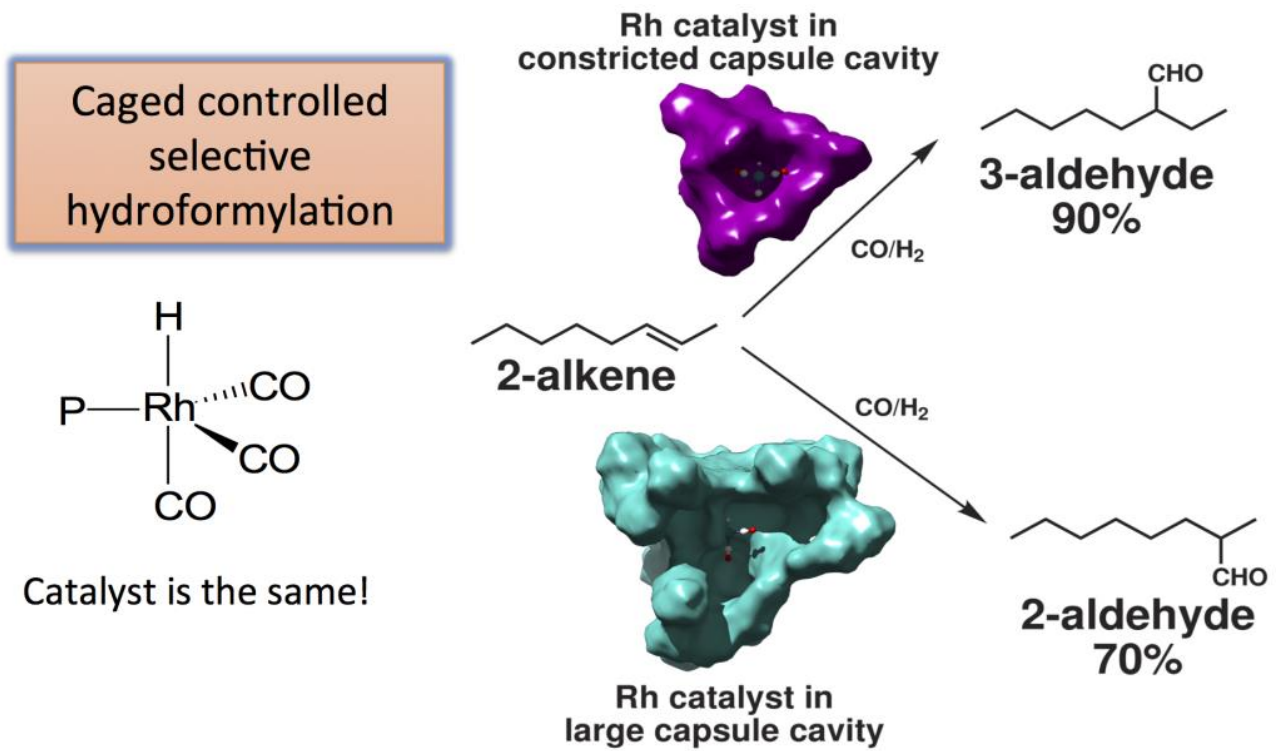

Figure 2. Example of caged controlled selectivity from the Reek group. 


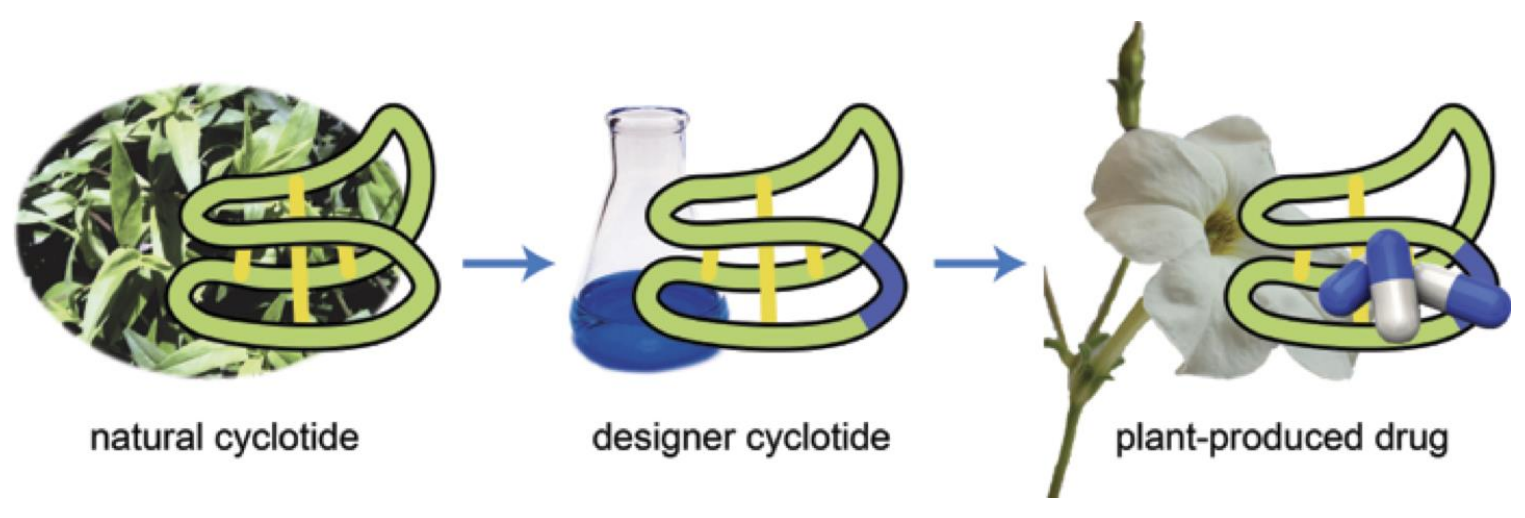

Figure 3. The strategy of the Craik group for cyclotides grafted bioactive peptides.

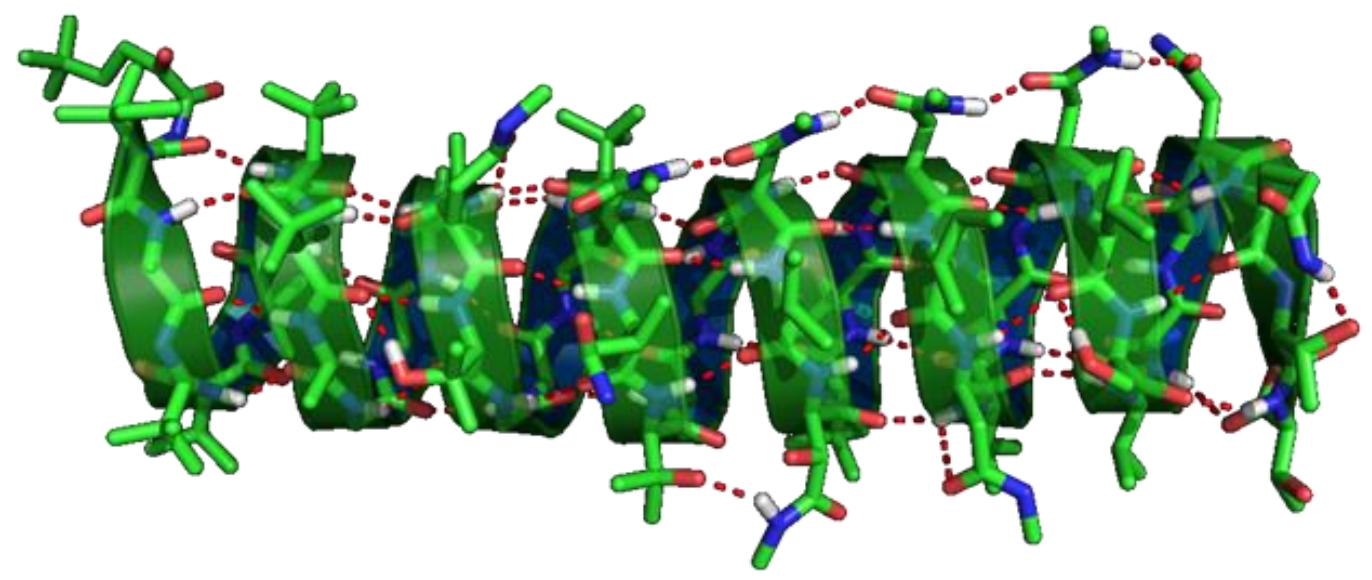

Figure 4. The helical structure of a polytheonamide peptide is shown. Understanding the bacterial synthesis of these super-hydrophobic peptides is a target for the Piel group. 

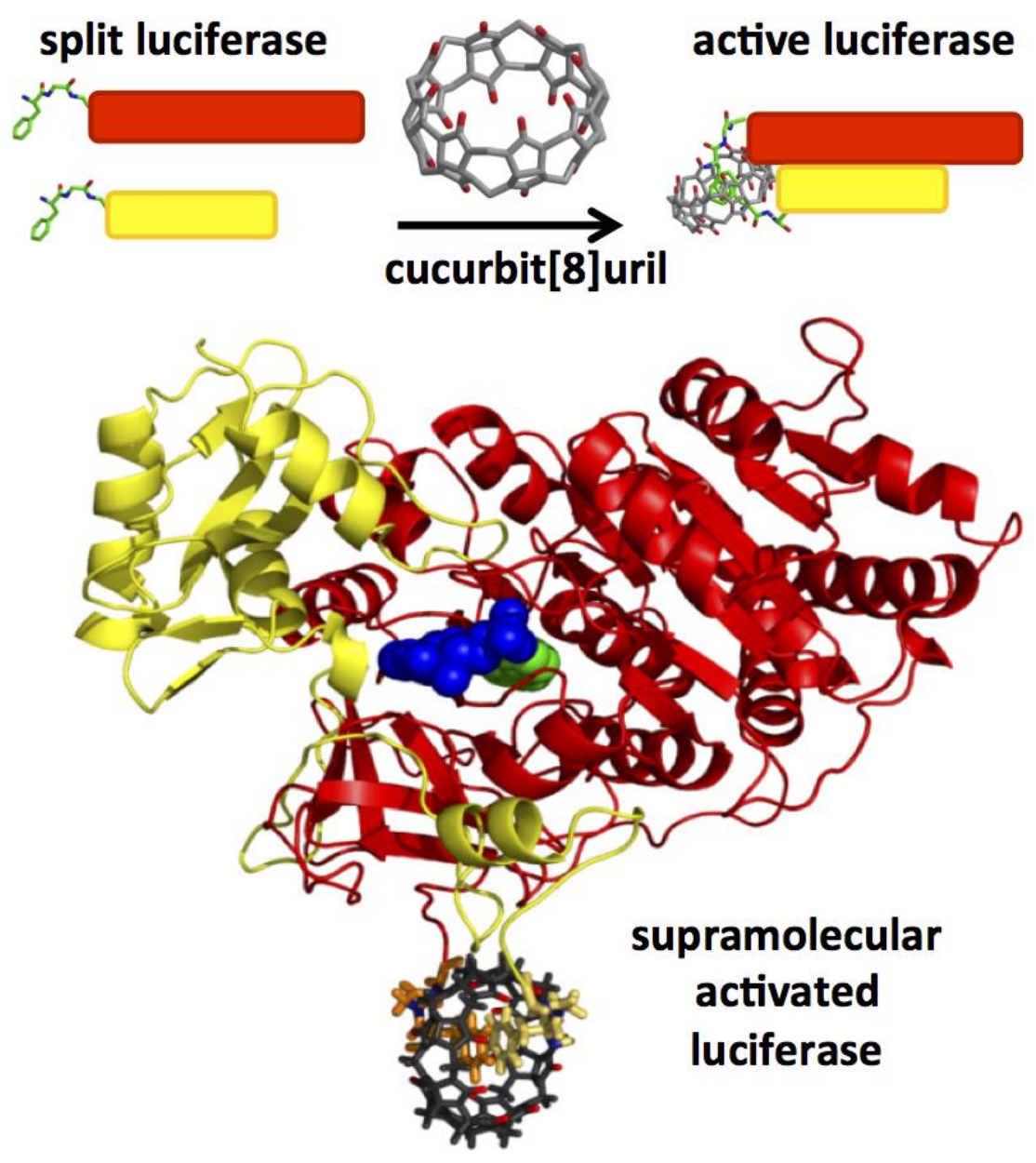

Figure 5. The cucurbit[8] uril platform for supramolecular protein assembly from the Brunsveld group. 